Rev. Bras. Saúde Prod. Anim., Salvador, v.15, n.2, p.415-424 abr./jun., 2014 http://www.rbspa.ufba.br ISSN 15199940

\title{
Utilização de probiótico e monensina sódica sobre o desempenho produtivo e características de carcaça de bovinos Nelore terminados em confinamento
}

\author{
Use of feeding direct-fed microbials and monensin on feedlot performance and carcass \\ traits of Nellore cattle
}

\author{
RIGOBELO, Everlon Cid ${ }^{1}$; PEREIRA, Murillo Ceola Stefano²; VICARI, Daniel Vitor \\ Ferreira $^{2}$; MILLEN, Danilo Domingues ${ }^{2 *}$
}

\author{
${ }^{1}$ Universidade Estadual Paulista, Faculdade de Ciências Agrárias e Veterinárias, Jaboticabal, São Paulo, Brasil. \\ ${ }^{2}$ Universidade Estadual Paulista, Dracena, São Paulo, Brasil. \\ *Endereço para correspondência: danilomillen@dracena.unesp.br
}

RESUMO

O objetivo com este estudo foi avaliar o efeito do probiótico a base de bactérias produtoras de lactato (DBR) e da monensina sódica (MON) sobre o desempenho produtivo e características de carcaça de bovinos Nelore terminados em confinamento. Foram utilizados 18 machos, não castrados, com média de idade de 18 meses e $362,0 \pm 30,0 \mathrm{~kg}$ de peso vivo inicial, divididos em três tratamentos: 1 ) $2 \mathrm{~g}$ de DBR; 2) $1 \mathrm{~g}$ de DBR + 138mg de MON e; 3 ) $275 \mathrm{mg}$ de MON, caracterizando delineamento inteiramente casualizado, com 6 animais por tratamento, divididos em 18 baias ( 1 animal/baia) em sistema de alimentação do tipo Calan Gate. O experimento teve duração de 84 dias, os animais foram pesados e submetidos a avaliações de ultrassonografia a cada 28 dias. Não houve efeito dos aditivos alimentares em relação ao peso vivo final e consumo de massa seca em percentagem do peso vivo. $\mathrm{O}$ ganho de peso diário foi menor nos primeiros 28 e 56 dias de estudo para animais que consumiram MON e DBR+MON, porém não foram observadas diferenças entre os tratamentos no período total. Animais alimentados com DBR+MON apresentaram maior consumo de massa seca durante todo o estudo, porém pior conversão alimentar que aqueles alimentados com DBR ou MON. Animais alimentados com DBR+MON apresentaram menor rendimento de carcaça que aqueles suplementados com DBR apenas e animais suplementados com MON tiveram maior espessura de gordura subcutânea ao final do estudo. A suplementação com o DBR apenas, pode ser uma alternativa para substituir a monensina.

Palavras-chave: aditivos alimentares, ionóforo, Zebu

\section{SUMMARY}

The objective of this study was to evaluate the effect of probiotic based on lactate-producing bacteria (DBR) and sodium monensin (MON) on feedlot performance and carcass traits of feedlot Nellore cattle. The experiment was designed as a completely randomized design, replicated 6 times, in which 18 18-months-old yearling Nellore bulls $(362,0 \pm 30,0 \mathrm{~kg})$ were fed in individual pens for 84 days ( 1 animal/pen) in Calan gate system according to the treatments: 1) $2 \mathrm{~g}$ of DBR; 2) $1 \mathrm{~g}$ of DBR $+138 \mathrm{mg}$ of MON and; 3) $275 \mathrm{mg}$ of MON. The experiment lasted 84 days; the animals were both weighed and evaluated by ultrasound every 28 days. There was no effect of feed additives on final body weight and dry matter intake, expressed as percentage of body weight. The average daily gain was lower in the first 28 and 56 days of the study for animals fed MON and MON+DBR, but overall, no differences were observed between treatments were detected. Animals fed MON+DBR showed higher dry matter intake throughout the study, but lower feed conversion than those fed with DBR or MON. Animals fed $\mathrm{MON}+\mathrm{DBR}$ had decreased dressing percentage than those supplemented with DBR only. In addition, animals fed only MON had thicker back fat by the end of the study. Supplementation with DBR may eventually be an alternative to replace MON.

Keywords: ionophore, feed additives, Zebu 
Rev. Bras. Saúde Prod. Anim., Salvador, v.15, n.2, p.415-424 abr./jun., 2014 http://www.rbspa.ufba.br ISSN 15199940

\section{INTRODUÇ̃̃O}

A monensina sódica (MON) é um ionóforo muito utilizado em vários países, entre eles Estados Unidos, Brasil, Austrália e Nova Zelândia, com o intuito de evitar problemas decorrentes de desordens digestivas como a acidose ruminal e melhorar a eficiência produtiva de bovinos de corte confinados.

Contudo alguns países, principalmente os da União Europeia baniram desde 2006 (artigo $\mathrm{n}^{\circ} 11$, regulamento $1831 / 2003$ ) o uso dos ionóforos como promotores de crescimento,por serem classificados como antibiótico (OJEU, 2003), devido ao possível potencial de transferência de resistência antimicrobiana dos animais para os seres humanos, o que pode impactar diretamente sobre a saúde pública (KELLY et al., 2004).

Considerando que em 2013 o Brasil movimentou mais de US\$ 742 milhões com exportações de carne bovina para a União Europeia (ABIEC, 2013) e que segundo Millen et al. (2009) os ionóforos são os principais aditivos alimentares utilizados em $100 \%$ dos confinamentos brasileiros, torna-se necessário à busca por novas alternativas para substituir o uso dos ionóforos por novas técnicas que melhorem o desempenho produtivo apresentando mesma eficiência produtiva e sem provocar qualquer tipo de risco à saúde humana.

Desta maneira, uma alternativa ao uso dos ionóforos é o fornecimento de probióticos, aditivos alimentares a base de cultura de microrganismos vivos que beneficiam $o$ animal hospedeiro. Muitos estudos relataram a importância do uso de probióticos na melhora dos índices produtivos, principalmente aqueles que continham bactérias do gênero Ruminobacter amylophilum, Ruminobacter succinogenes e Succinovibrio dextrinosolvens, as quais agem na fermentação ruminal do amido, celulose,pectina e maltose (CATO et al. 1978; Van HOUTERT, 1993), além da importância do Bacillus cereus, no aumento do estímulo do sistema imunológico (HUYNH et al., 2004), e da manutenção e regulação do $\mathrm{pH}$ ruminal devido a produção de lactato pelas bactérias Lactobacillus acidophilus e Enterococcus faecium (KREHBIEL et al., 2003; YANG et al., 2004), tornando a utilização de $\mathrm{H}^{+}$mais eficiente (LILA et al., 2004).

Assim sendo, o objetivo deste estudo foi avaliar a utilização do probiótico a base de bactérias que produzem lactato (DBR), em substituição ou associação com aMON sobre o desempenho produtivo e características de carcaça de bovinos Nelore terminados em confinamento.

\section{MATERIAL E MÉTODOS}

Todos os procedimentos que envolveram os animais foram realizados dentro das diretrizes e aprovados pelo Comitê de Ética em Pesquisa (CEP) da FZEA/USP.

$O$ experimento foi realizado no Departamento de Zootecnia, da Faculdade de Zootecnia e Engenharia de Alimentos, Universidade de São Paulo - USP, em Pirassununga - SP. Foram utilizados 18 machos, não castrados, com média de idade de 18 meses e $362,0 \pm 30,0 \mathrm{~kg}$ de peso vivo inicial, distribuídos aleatoriamente em 18 baias individuais (1 animal/baia), cobertas, em sistema de alimentação tipo Calan Gate, com acesso a sombra e água. 
Rev. Bras. Saúde Prod. Anim., Salvador, v.15, n.2, p.415-424 abr./jun., 2014 http://www.rbspa.ufba.br ISSN 15199940

Os animais foram alimentados de forma ad libitum, duas vezes ao dia (8 e 16 horas), em que foi fornecida ração que continha $18 \%$ de bagaço de cana e $82 \%$ de ingredientes concentrados, a qual foi formulada segundo o LRNS nível 2 (Large Ruminant Nutrition System, FOX et al., 2004) conforme descrito na Tabela 1. Com relação aos nutrientes da dieta, a proteína bruta foi determinada segundo o AOAC (1990), a fibra em detergente neutro foi determinada de acordo com Van Soest et al. (1991), e os demais nutrientes mostrados na Tabela 1 foram estimados por equações do LRNS (FOX et al., 2004). Além da dieta, os animais receberam diariamente $100 \mathrm{~g}$ de uma mistura contendo fubá de milho, pelo qual foram fornecidas as quantidades específicas de MON (Rumensin, Elanco Animal
Health, Indianapolis, IN, EUA) e probiótico $\quad\left(\mathrm{DBR}^{\circledR}, \quad\right.$ Imeve Sáude e Biotecnologia Animal, Jaboticabal, SP, Brasil) composto por Ruminobacter amylophilum (3,0x10 $\left.{ }^{11} \mathrm{UFC} / \mathrm{kg}\right), \quad$ Ruminobacter succinogenes $\quad\left(3,0 \times 10^{11} \mathrm{UFC} / \mathrm{kg}\right)$, Succinovibrio dextrinosolvens $\left(4,4 \times 10^{11} \mathrm{UFC} / \mathrm{kg}\right), \quad$ Bacillus cereus (3,5x $\left.10^{11} \mathrm{UFC} / \mathrm{kg}\right), \quad$ Lactobacillus acidophilus $\quad\left(3,5 \times 10^{11} \mathrm{UFC} / \mathrm{kg}\right)$, e Enterococcus faecium $\left(3,5 \times 10^{11} \mathrm{UFC} / \mathrm{kg}\right)$ conforme os tratamentos a seguir: 1) $2 \mathrm{~g}$ de DBR; 2) $1 \mathrm{~g}$ de DBR + $138 \mathrm{mg}$ de MON e; 3) $275 \mathrm{mg}$ de MON. Os $100 \mathrm{~g}$ de fubá de milho fornecidos como veículo estão considerados na fórmula da dieta experimental mostrada na Tabela 1, como parte dos grãos de milho seco quebrados.

Tabela 1. Composição e análise química da dieta experimental

\begin{tabular}{|c|c|}
\hline Ingredientes & $\%$ na Matéria Seca \\
\hline Bagaço de cana in natura & 18,0 \\
\hline Grãos de milho seco quebrados & 42,5 \\
\hline Farelo de soja & 7,0 \\
\hline Casca de soja peletizada & 30,0 \\
\hline Ureia & 1,0 \\
\hline Núcleo mineral $^{1}$ & 1,5 \\
\hline \multicolumn{2}{|l|}{ Composição nutricional } \\
\hline Proteína bruta (\%) & 14,2 \\
\hline Proteína degradável no rúmen (\%) & 9,05 \\
\hline Nutrientes digestíveis totais (\%) & 72,4 \\
\hline Fibra em detergente neutro (\%) & 26,7 \\
\hline $\mathrm{Ca}(\%)$ & 0,64 \\
\hline $\mathrm{P}(\%)$ & 0,29 \\
\hline
\end{tabular}

As misturas foram preparadas em misturador com capacidade de $100 \mathrm{~kg}$ e acondicionadas em sacos plásticos, devidamente identificados, na quantidade a ser fornecida diariamente aos animais (100g).
A mistura entre o fubá de milho e os aditivos foi fornecida no primeiro trato do dia ( 8 horas) sobre a ração total, não sendo misturada a esta, com o objetivo de garantir o consumo integral de seus componentes. 
O consumo de massa natural foi determinado diariamente, calculando-se a diferença entre a quantidade de ração total fornecida e as sobras do dia posterior, sendo o fornecimento diário ajustado de forma a manter entre $5 \mathrm{e}$ $10 \%$ de sobras em relação ao total fornecido. A ingestão de massa seca média foi expressa em quilogramas e a em porcentagem do peso vivo. Dessa forma, foi calculado o ganho de peso diário, utilizando os dados da pesagem inicial e final divididos pelo tempo de confinamento. A conversão alimentar foi obtida pela divisão do consumo de massa seca total pelo ganho de peso vivo total.

Os animais foram pesados a cada 28 dias, após jejum de sólidos de 16 horas, e submetidos a avaliações de ultrassonografia, utilizando-se unidades de ultrassom veterinário "Pie Medical Modelo 200", e óleo vegetal como acoplante acústico, para verificar o desenvolvimento da área de olho de lombo (AOL), tecido adiposo subcutâneo (EGS) no músculo Longissimus dorsi (contra-filé) entre as $12^{\mathrm{a}}$ e $13^{\mathrm{a}}$ costelas e o desenvolvimento do tecido adiposo da garupa (EGP8) sobre o músculo Bíceps femoris (picanha), para posteriormente calcularse os ganhos diários de AOL, EGS e EGP8.

Os animais foram abatidos em frigorífico comercial, em que foi mensurado o peso de carcaça quente e rendimento de carcaça, calculado por meio da divisão do peso de carcaça quente obtido no frigorifico pelo peso vivo final multiplicado por 100 .

O delineamento experimental foi em inteiramente casualizado $\mathrm{e}$ as baias foram consideradas as unidades experimentais para todas as variáveis deste estudo. Foram realizados testes de normalidade e de heterogeneidade de variâncias antes de se proceder a análise de variância e quando necessário, os dados foram transformados.

Os dados foram analisados de forma cumulativa e apresentados em três períodos (inicial: 0 a 28 dias, intermediário: 0 a 56 dias, e total: 0 a 84 dias). Utilizou-se o PROC MIXED do SAS (STATISTICAL ANALYSIS SYSTEM, 2011), considerando 5\% como nível de significância.

\section{RESULTADOS E DISCUSSÃO}

Em relação ao desempenho produtivo (Tabela 2), não houve efeito $(\mathrm{P}>0,05)$ dos aditivos alimentares segundo as variáveis: peso vivo inicial, peso vivo final, e consumo de massa seca em percentagem do peso vivo. Contudo, o ganho de peso diário foi menor nos períodos inicial $(\mathrm{P}=0,02) \quad \mathrm{e}$ intermediário $(\mathrm{P}=0,04)$ em animais alimentados com MON e DBR+MON quando comparado àqueles suplementados apenas com DBR. Isso pode ter ocorrido devido a melhor conversão alimentar de bovinos alimentados com DBR nos primeiros 56 dias de estudo, o que também pode ter levado ao maior ganho de AOL (Tabela $3)$ por esses animais nos primeiros 28 dias de experimento. Desta forma, o custo para ganho de $1 \mathrm{~kg}$ de peso vivo foi menor para bovinos alimentados com DBR nos primeiros 28 dias de estudo (Tabela 2). Porém, quando considerado o período total, não houve efeito dos tratamentos sobre o ganho de peso diário $(\mathrm{P}=0,38)$ e consumo de massa seca em percentagem do peso vivo $(\mathrm{P}=0,11)$, o que leva a inferência de queda no desempenho dos animais alimentados com DBR nos últimos 28 dias de estudo. Animais alimentados com DBR e MON tiveram melhor conversão alimentar que aqueles 
Rev. Bras. Saúde Prod. Anim., Salvador, v.15, n.2, p.415-424 abr./jun., 2014 http://www.rbspa.ufba.br ISSN 15199940

alimentados com $\mathrm{DBR}+\mathrm{MON}$ quando considerado o período total $(\mathrm{P}=0,01)$, o que pode ser explicado pelo menor consumo de massa seca em $\mathrm{kg}$ por parte desses animais $(\mathrm{P}=0,05)$. Além disso, animais alimentados com $\mathrm{DBR}+\mathrm{MON}$ apresentaram o maior custo para ganho de $1 \mathrm{~kg}$ de peso vivo, o que mostra que a associação dos dois aditivos não foi economicamente benéfica neste estudo.

A melhora na conversão alimentar em bovinos alimentados com MON pode ser explicada em parte pelos seguintes fatos: redução da produção de metano, que ocorre devido a redução na população ruminal de bactérias Gram- positivas,o que resulta em menores perdas de energia (ELLIS et al., 2008); aumento da produção de propionato no rúmen (OLIVEIRA et al., 2007) e diminuição da desaminação (RUSSEL \& MARTIN, 1984). A melhora na conversão alimentar em animais suplementados com DBR pode ser atribuída a maior produção total de ácidos graxos de cadeia curta, já que seu modo de ação inclui o aumento na digestibilidade de amido e fibra (CATO et al. 1978; Van HOUTERT, 1993), além de melhora do ambiente ruminal, em termos de $\mathrm{pH}$, para fermentação.

Tabela 2. Desempenho produtivo de bovinos Nelore confinados suplementados com probiótico e monensina sódica

\begin{tabular}{|c|c|c|c|c|c|c|}
\hline \multirow{2}{*}{ Variável } & \multirow{2}{*}{$\begin{array}{l}\text { Período } \\
\text { (dias) }\end{array}$} & \multicolumn{3}{|c|}{ Tratamentos } & \multirow{2}{*}{$\mathrm{EPM}^{4}$} & \multirow{2}{*}{$\begin{array}{l}\text { Valor } \\
\text { de P }\end{array}$} \\
\hline & & $\mathrm{DBR}^{1}$ & $\mathrm{DBR}+\mathrm{MON}^{2}$ & $\mathrm{MON}^{3}$ & & \\
\hline Peso vivo inicial (kg) & & 359,00 & 368,00 & 368,00 & 11,86 & 0,82 \\
\hline \multirow{3}{*}{ Peso vivo final (kg) } & $0-28$ & 423,33 & 424,00 & 422,67 & 12,77 & 1,00 \\
\hline & $0-56$ & 487,20 & 474,33 & 480,33 & 12,54 & 0,58 \\
\hline & $0-84$ & 520,67 & 526,00 & 532,33 & 14,86 & 0,19 \\
\hline \multirow{3}{*}{ Ganho de peso diário $(\mathrm{kg})$} & $0-28$ & $2,30^{\mathrm{a}}$ & $2,00^{\mathrm{b}}$ & $1,95^{\mathrm{b}}$ & 0,12 & 0,03 \\
\hline & $0-56$ & $2,29^{\mathrm{a}}$ & $1,90^{\mathrm{b}}$ & $2,01^{\mathrm{b}}$ & 0,14 & 0,04 \\
\hline & $0-84$ & 1,93 & 1,88 & 1,96 & 0,09 & 0,38 \\
\hline \multirow{3}{*}{ Consumo de massa seca $(\mathrm{kg})$} & $0-28$ & $10,30^{\mathrm{a}}$ & $10,19^{\mathrm{a}}$ & $9,58^{\mathrm{b}}$ & 0,28 & 0,02 \\
\hline & $0-56$ & $10,44^{\mathrm{a}}$ & $10,82^{\mathrm{a}}$ & $9,92^{\mathrm{b}}$ & 0,34 & 0,04 \\
\hline & $0-84$ & $10,79^{\mathrm{b}}$ & $11,31^{\mathrm{a}}$ & $10,56^{\mathrm{b}}$ & 0,20 & 0,05 \\
\hline \multirow{3}{*}{$\begin{array}{l}\text { Consumo de massa seca em } \% \\
\text { do peso vivo }\end{array}$} & $0-28$ & 2,63 & 2,57 & 2,42 & 0,09 & 0,26 \\
\hline & $0-56$ & 2,48 & 2,56 & 2,34 & 0,15 & 0,09 \\
\hline & $0-84$ & 2,45 & 2,53 & 2,35 & 0,12 & 0,11 \\
\hline \multirow{3}{*}{$\begin{array}{l}\text { Custo para ganho de } 1 \mathrm{~kg} \text { de peso } \\
\text { vivo }(\mathrm{R} \$)\end{array}$} & $0-28$ & $4,98^{\mathrm{b}}$ & $5,67^{\mathrm{a}}$ & $5,42^{\mathrm{a}}$ & 0,69 & 0,01 \\
\hline & $0-56$ & $5,17^{\mathrm{b}}$ & $6,20^{\mathrm{a}}$ & $5,36^{\mathrm{b}}$ & 0,52 & 0,01 \\
\hline & $0-84$ & $6,18^{\mathrm{a}}$ & $6,63^{\mathrm{b}}$ & $5,95^{\mathrm{a}}$ & 0,47 & 0,02 \\
\hline \multirow{3}{*}{ Conversão alimentar $(\mathrm{kg} / \mathrm{kg})$} & $0-28$ & $4,48^{\mathrm{b}}$ & $5,09^{\mathrm{a}}$ & $4,91^{\mathrm{a}}$ & 0,58 & 0,03 \\
\hline & $0-56$ & $4,56^{\mathrm{b}}$ & $5,69^{\mathrm{a}}$ & $4,94^{\mathrm{b}}$ & 1,00 & 0,01 \\
\hline & $0-84$ & $5,61^{\mathrm{b}}$ & $6,02^{\mathrm{a}}$ & $5,40^{\mathrm{b}}$ & 1,19 & 0,01 \\
\hline
\end{tabular}

${ }^{\mathrm{a}, \mathrm{b}}$ Médias seguidas por letras diferentes nas linhas diferem $(\mathrm{P}<0,05)$ pelo teste Tukey.

${ }^{1}$ Probiótico DBR ${ }^{\circledR} ;{ }^{2}$ Probiótico DBR ${ }^{\circledR}+$ Monensina; ${ }^{3}$ Monensina; ${ }^{4}$ Erro padrão médio. 
Rev. Bras. Saúde Prod. Anim., Salvador, v.15, n.2, p.415-424 abr./jun., 2014 http://www.rbspa.ufba.br ISSN 15199940

Tabela 3. Características de carcaça de bovinos Nelore confinados suplementados com probiótico e monensina sódica

\begin{tabular}{|c|c|c|c|c|c|c|}
\hline \multirow{2}{*}{ Variável } & \multirow{2}{*}{$\begin{array}{l}\text { Subperíodo } \\
\text { (dias) }\end{array}$} & \multicolumn{3}{|c|}{ Tratamentos } & \multirow{2}{*}{$\mathrm{EPM}^{4}$} & \multirow{2}{*}{$\begin{array}{c}\text { Valor de } \\
\text { P }\end{array}$} \\
\hline & & $\mathrm{DBR}^{1}$ & $\mathrm{DBR}^{2} \mathrm{MON}^{2}$ & $\mathrm{MON}^{3}$ & & \\
\hline Peso de carcaça quente $(\mathrm{kg})$ & & 292,87 & 285,22 & 291,53 & 9,19 & 0,22 \\
\hline Rendimento de carcaça (\%) & & $55,98^{\mathrm{a}}$ & $54,22^{\mathrm{b}}$ & $54,76^{\mathrm{ab}}$ & 0,31 & 0,06 \\
\hline $\mathrm{AOL}^{5}$ inicial $\left(\mathrm{cm}^{2}\right)$ & & 56,62 & 55,80 & 52,65 & 2,74 & 0,55 \\
\hline \multirow{3}{*}{ AOL final $\left(\mathrm{cm}^{2}\right)$} & $0-28$ & 63,22 & 60,20 & 58,58 & 2,55 & 0,42 \\
\hline & $0-56$ & 66,28 & 68,03 & 68,83 & 3,01 & 0,84 \\
\hline & $0-84$ & 80,65 & 77,80 & 79,95 & 3,56 & 0,84 \\
\hline \multirow{3}{*}{ Ganho de AOL ( $\left.\mathrm{cm}^{2} / \mathrm{dia}\right)$} & $0-28$ & $0,24^{\mathrm{a}}$ & $0,16^{\mathrm{b}}$ & $0,21^{\mathrm{ab}}$ & 0,04 & 0,04 \\
\hline & $0-56$ & 0,23 & 0,25 & 0,29 & 0,03 & 0,12 \\
\hline & $0-84$ & 0,29 & 0,28 & 0,33 & 0,03 & 0,19 \\
\hline $\mathrm{EGS}^{6}$ inicial $(\mathrm{mm})$ & & 0,28 & 0,54 & 0,24 & 0,23 & 0,64 \\
\hline \multirow{3}{*}{ EGS final (mm) } & $0-28$ & $1,88^{\mathrm{b}}$ & $2,28^{a}$ & $2,10^{\mathrm{ab}}$ & 0,37 & 0,03 \\
\hline & $0-56$ & $2,98^{\mathrm{b}}$ & $3,03^{\mathrm{b}}$ & $3,80^{\mathrm{a}}$ & 0,55 & 0,01 \\
\hline & $0-84$ & $4,01^{\mathrm{b}}$ & $4,38^{\mathrm{b}}$ & $5,31^{\mathrm{a}}$ & 0,39 & 0,06 \\
\hline \multirow{3}{*}{ Ganho de EGS (mm/dia) } & $0-28$ & $0,055^{\mathrm{ab}}$ & $0,064^{\mathrm{a}}$ & $0,042^{b}$ & 0,009 & 0,03 \\
\hline & $0-56$ & 0,050 & 0,047 & 0,050 & 0,009 & 0,95 \\
\hline & $0-84$ & 0,043 & 0,047 & 0,036 & 0,006 & 0,22 \\
\hline $\mathrm{P}^{7}$ inicial $(\mathrm{mm})$ & & 0,93 & 1,20 & 1,50 & 0,33 & 0,18 \\
\hline \multirow{3}{*}{ P8 final (mm) } & $0-28$ & 3,22 & 3,26 & 3,58 & 0,56 & 0,45 \\
\hline & $0-56$ & $5,34^{\mathrm{a}}$ & $4,88^{\mathrm{b}}$ & $5,36^{\mathrm{a}}$ & 0,37 & 0,07 \\
\hline & $0-84$ & 6,40 & 6,38 & 6,63 & 0,93 & 0,58 \\
\hline \multirow{3}{*}{$\begin{array}{l}\text { Ganho de } \\
(\mathrm{mm} / \text { dia })\end{array}$} & $0-28$ & 0,082 & 0,074 & 0,074 & 0,008 & 0,42 \\
\hline & $0-56$ & 0,082 & 0,066 & 0,069 & 0,012 & 0,11 \\
\hline & $0-84$ & 0,065 & 0,062 & 0,061 & 0,009 & 0,80 \\
\hline
\end{tabular}

${ }^{\mathrm{a}, \mathrm{b}}$ Médias seguidas por letras diferentes nas linhas diferem $(\mathrm{P}<0,05)$ pelo teste Tukey.

${ }^{1}$ Probiótico DBR ${ }^{\circledR} ;{ }^{2}$ Probiótico DBR ${ }^{\circledR}+$ Monensina; ${ }^{3}$ Monensina; ${ }^{4}$ Erro padrão médio; ${ }^{5}$ Área de olho de lombo; ${ }^{6}$ Espessura de gordura subcutânea; ${ }^{7}$ Bíceps femoris.

No entanto, com base nos resultados obtidos neste estudo, a associação entre MON e DBR promoveu efeito antagônico no que diz respeito à conversão alimentar. Como a dose de cada um dos aditivos testados neste tratamento foi a metade da dose fornecida aos animais que receberam ou um ou outro aditivo, isto pode ter colaborado para reduzir os efeitos de ambos sobre o meio ruminal. A existência de antagonismo entre DBR e MON sobre a fermentação ruminal não está bem clara, e precisa ser confirmada em outros estudos.

Contudo, muitos dos trabalhos presentes na literatura não encontraram relação entre os probióticos e MON sobre o desempenho produtivo de bovinos, entre eles o de Justos Neto \& Rossi Junior (2008), que avaliaram o fornecimento de probiótico (Saccharomyces cerevisiae) e MON para novilhos confinados, não encontrando efeito dos tratamentos no peso vivo final (415 e 407kg), ganho de peso diário $(1,12$ e $1,09 \mathrm{~kg})$, conversão alimentar $(7,15$ e 6,35$)$ e consumo de 
Rev. Bras. Saúde Prod. Anim., Salvador, v.15, n.2, p.415-424 abr./jun., 2014 http://www.rbspa.ufba.br ISSN 15199940

massa seca $(7,81$ e $6,74 \mathrm{~kg})$. Kuss et al. (2009) não encontrou relação entre o fornecimento de probiótico $(S$. cerevisiae), MON e probiótico+MON em novilhos (1/2Pardo Suíço $+1 / 2$ Canchim, $1 / 2$ Purunã $+1 / 2$ Canchim e $3 / 4$ Purunã $+1 / 4$ Canchim) confinados, sobre o peso vivo final, ganho de peso diário e conversão alimentar, tanto nos períodos parciais (inicial, intermediário) quanto no período total de confinamento. Gomes et al. (2011) também não observaram efeito do probiótico ( $S$. cerevisiae), MON e da combinação dos dois aditivos no peso vivo final, ganho de peso diário $\mathrm{e}$ consumo de massa seca, entretanto, relataram tendência do probiótico a piorar a conversão alimentar de novilhos Nelore confinados. Erasmus et al. (2005) concluíram que a suplementação com probiótico $(S$. cerevisiae), MON ou ambos não interferiu sobre a produção e composição do leite de vacas Holandesas, contudo, os padrões de fermentação ruminal foram afetados,sendo observado aumento da concentração de propionato nos três tratamentos comparados ao grupo controle.

Contrariando a maioria dos resultados apresentados e corroborando com os dados do presente experimento, Krehbiel et al. (2003) compilou os resultados de vários experimentos com bovinos de corte em confinamento que utilizaram probióticos a base de Lactobacillus, Enterococcus, Streptococcus, Bifidobacterium e Saccharomyces cerevisiae, sugerindo melhora de $2 \%$ na conversão alimentar de bovinos alimentados com rações contendo probióticos, enquanto que o efeito sobre o consumo de massa seca se mostrou inconsistente. Por outro lado, os resultados obtidos com a utilização da MON são consistentes. Em meta-analise feita por Duffield et al.
(2012) avaliando um total de 40 artigos e 24 relatórios técnicos sobre o impacto da MON no crescimento e terminação de bovinos de corte confinados, estes observaram melhora de $6,4 \%$ na conversão alimentar, porém, este aumento variou apenas entre 2,5 a 3,5\% nas ultimas duas décadas. No mesmo estudo também foi detectada redução no consumo de massa seca na ordem de $3 \%$ e aumento de $2,5 \%$ no ganho de peso diário, comparados a animais que não foram suplementados com 0 ionóforo. Desta forma, apesar de não haver diferenças entre os diferentes tratamentos com relação ao ganho de peso diário no presente estudo, bovinos alimentados apenas com MON apresentaram melhor conversão alimentar e menor consumo de massa seca em $\mathrm{kg}$, o que corrobora com os dados de Duffield et al. (2012). Assim, como a suplementação de apenas DBR promoveu respostas similares a suplementação de MON, o probiótico em questão pode ser uma eventual alternativa ao uso de ionóforos.

Os dados das características de carcaça estão apresentados na Tabela 3. Não houve efeito dos tratamentos sobre o peso de carcaça quente $(\mathrm{P}>0,05)$. Da mesma forma, se considerado todo o período experimental, não foi observado efeitos dos tratamentos $(\mathrm{P}>0,05)$ sobre as variáveis: AOL inicial, AOL final, ganho de AOL, EGS inicial, ganho de EGS, EGP8 inicial, EGP8 final, ganho de EGP8.

$\mathrm{O}$ rendimento de carcaça foi influenciado $(\mathrm{P}=0,06)$ pelos tratamentos, em que animais suplementados com DBR apresentaram maior rendimento que aqueles alimentados com DBR+MON, porém similar àqueles que consumiram MON (Tabela 3). O menor rendimento de carcaça apresentado pelos animais alimentados com DBR + MON pode ser explicado pela menor AOL, 
Rev. Bras. Saúde Prod. Anim., Salvador, v.15, n.2, p.415-424 abr./jun., 2014 http://www.rbspa.ufba.br ISSN 15199940

numericamente, apresentada por estes ao final do estudo.

A EGS final foi afetada no período inicial $(\mathrm{P}=0,03)$, intermediário $(\mathrm{P}=0,01)$ e total $(\mathrm{P}=0,06)$, em que animais alimentados apenas com DBR apresentaram sempre menor EGS que aqueles alimentados com MON. Esta também pode ser uma das explicações da razão pela quais animais alimentados apenas com DBR apresentaram maior ganho de peso diário nos primeiros 56 dias. A maior deposição de gordura no músculo $L$. dorsi pode ter sido devido ao fato de que a MON aumenta a produção total de ácidos graxos de cadeia curta, especialmente pela concomitante redução da produção de metano, por modificar a população bacteriana ruminal (OLIVEIRA et al., 2007), o que resultam em melhora da eficiência alimentar (Tabela 2) e maior energia disponível.

Kuss et al. (2009) relataram que a suplementação de probiótico (S. cerevisiae), MON e a associação de probiótico+MON para bovinos confinados também não afetou o peso de carcaça quente e a AOL. Entretanto, contrariando os dados do presente estudo, os autores não observaram efeito dos aditivos no rendimento de carcaça, sugerindo um possível aumento na dosagem do probiótico, uma vez que os resultados na literatura são contraditórios.

Contudo, Gomes et al. (2009) observou diferença em bovinos Nelore suplementados com probiótico $(S$. cerevisiae), MON e probiótico+MON em relação ao rendimento de carcaça, constatando que o tratamento com o probiótico apresentou o maior rendimento $(56,9 \%)$ não diferenciando do MON $(56,4 \%)$, que por sua vez, não diferiu do probiótico+MON (55,5\%) Estes resultados foram similares aos encontrados no presente estudo.
Todavia, os autores não relataram efeito dos respectivos aditivos em relação à EGS final. Desta maneira, parece haver evidências anteriores de que a associação de MON com aditivos probióticos promove algum tipo de efeito antagônico, o qual afetou tanto o rendimento de carcaça quanto a conversão alimentar no presente estudo. Em geral, estes estudos suportam os resultados do presente experimento e indicam que a suplementação com DBR ou MON apresentarem resultados similares em termos de desempenho se considerado $\mathrm{o}$ período total de experimento, não impactando as características de carcaça, com exceção da EGS final.

Assim sendo, pode-se concluir que a suplementação com o probiótico DBR pode ser uma eventual alternativa ao uso da MON, uma vez que animais alimentados com um ou outro aditivo apresentaram desempenho produtivo e características de carcaça semelhantes. A associação dos dois aditivos impacta negativamente sobre a conversão alimentar e rendimento de carcaça, e por isso o mecanismo de ação pelo qual este efeito é atingido, precisa ser estudado.

\section{REFERÊNCIAS}

ASSOCIAÇÃO BRASILEIRA DAS INDÚSTRIAS EXPORTADORAS DE CARNE - ABIEC. Estatísticas: exportações brasileiras de carne bovina. 2013. Disponível em: $<$ www.abiec.com.br>. Acesso em: 14 jan. 2014.

ASSOCIATION OF OFFICIAL ANALYTICAL CHEMISTS - AOAC. Official Methods of Analysis. $15^{\text {th }}$ ed. Arlington, 1990. 
Rev. Bras. Saúde Prod. Anim., Salvador, v.15, n.2, p.415-424 abr./jun., 2014 http://www.rbspa.ufba.br ISSN 15199940

CATO, E.P.; MOORE, W.E.C.; BRYANT, M.V. Designation of neotype strains for Bacteroides amylophilus Hamlin and Hungate 1956 and Bacteroides succinogenes Hungate 1950. International Journal of Sistematic Bacteriology, v.28, n.4, p.491-495, 1978.

DUFFIELD, T.F.; MERRIL, J.K.; BAGG, R.N. Meta-analysis of the effects of monensin in beef cattle on feed efficiency, body weight gain, and dry matter intake. Journal of Animal Science, v.90, p.4583-4592, 2012.

ELLIS, J.L.; DIJKSTRA, J.; KEBREAB, E.; BANNINK, A.; ODONGO, N. E.; MCBRIDE, B.W.; FRANCE, J. Aspects of rumen microbiology central to mechanistic modeling of methane production in cattle. Journal of Agricultural Science, v.146, p.213-233, 2008.

ERASMUS, L.J.; ROBINSONB, P.H.; AHMADIB, A.; HINDERS, R.; GARRETTD, J.E. Influence of prepartum and postpartum supplementation of a yeast culture and monensin, or both, on ruminal fermentation and performance of multiparous dairy cows. Animal Feed Science and Technology, v.122, p.219239, 2005.

FOX, D.G.; TEDESCHI, L.O.; TYLUTKI, T.P.; RUSSELL, J.B.; VAN AMBURGH, M.E.; CHASE, L.E.; PELL, A.N.; OVERTON, T.R. The Cornell Net Carbohydrate and Protein System model for evaluating herd nutrition and nutrient excretion. Animal Feed Science and Technology, v.112, p.29-78, 2004.

GOMES, R.C.; LEME, P.R.; SILVA, S.L.; ANTUNES, M.T.; GUEDES, C.F. Carcass quality of feedlot finished steers fed yeast, monensin, and the association of both additives. Arquivos Brasileiros de Medicina Veterinária e Zootecnia, v.61, p.648-654, 2009.

GOMES, R.C.; ANTUNES, M.T.; SILVA, S.L.; LEME, P.R. Desempenho e digestibilidade de novilhos zebuínos confinados recebendo leveduras vivas e monensina. Archivos de zootecnia, v.60, n.232, p.1077-1078, 2011.

HUYNH, A.; HONG, L.H.D.; CUTTING, S.M. The use of bacterial spore formers as probiotics. FEMS Microbiology, v.29, p.813-835, 2005.

JUSTUS NETO, C.; ROSSI JUNIOR, P. Influência da monensina sódica, probiótico (Saccharomyces cerevisiae) e complemento mineral orgânico (cromo) na dieta de novilhos confinados. Archives of Veterinary Science, v.13, n.4, p.274-279, 2008.

KELLY, L.L.; SMITH, D.L.; SNARY, E.L.; JOHNSON, J.A.; HARRIS, A.D.; WOOLDRIDGE, M.; MORRIS JUNIOR, J.G. Animal growth promoters: To ban or not to ban? A risk assessment approach. Journal of Antimicrobial, v.24, p.205-212, 2004.

KREHBIEL, C.R.; RUST, S.R.; ZHANG, G.; GILLILAND, S.E. Bacterial direct-fed microbials in ruminant diets: Performance response and mode of action. Journal of Animal Science, v.81, p.120-132, 2003.

KUSS, F.; MOLETTA, J.L.; PAULA, M.C.; MOURA, I.C.F.; ANDRADE, S.J.T.; SILVA, A.G.M. Desempenho e características de carcaça e da carne de novilhos não-castrados alimentados com ou sem adição de monensina e/ou probiótico à dieta. Ciência Rural, v.39, n.4, p.1180-1186, 2009. 
Rev. Bras. Saúde Prod. Anim., Salvador, v.15, n.2, p.415-424 abr./jun., 2014 http://www.rbspa.ufba.br ISSN 15199940

LILA, Z.A.; MOHAMMED, N.; YASUI, T.; KUROKAWA, Y.S.; ITABASHI, H. Effects of a twin strain of Saccharomyces cerevisiae live cells on mixed ruminal microorganism fermentation in vitro. Journal of Animal Science, v.82, p.1847-1854, 2004.

MILLEN, D.D.; PACHECO, R.D.L.; ARRIGONI, M.D.B.; GALYEAN, M.L.; VASCONCELOS, J.T. A snapshot of management practices and nutritional recommendations used by feedlot nutritionists in Brazil. Journal of Animal Science, v.87, p.3427-3439, 2009.

OFFICIAL JOURNAL OF THE EUROPEAN UNION - OJEU.

Regulation (EC) No 1831/2003 of the European Parliament and the Council of 22 of September of 2003 on Additives for Use in Animal Nutrition. Pages L268/29-L268/43 in OJEU of $10 / 18 / 2003$.

OLIVEIRA, M.V.M.; LANA, R.P.; EIFERT, E.C.; LUZ, D.F.; PEREIRA, J.C.; PÉREZ, J.R.O.; VARGAS

JUNIOR, F.M. Influência da monensina sódica no consumo e na digestibilidade de dietas com diferentes teores de proteína para ovinos. Revista

Brasileira de Zootecnia, v.36, p.643651, 2007.
RUSSELL, J.B.; MARTIN, S.A.

Effects of various methane inhibitors on the fermentation of amino acids by mixed rumen microganisms in vitro. Journal of Animal Science, v.59, p.1329-1338, 1984.

STATISTICAL ANALYSIS SYSTEM. SAS: user's guide: statistics. Version 9.3. Cary: SAS Institute inc., 2011.

VAN HOUTERT, M.F.J. The production and metabolism of volatile fatty acids by ruminants fed roughages: A review. Animal Feed Science and Technology, v.43, p.189-225, 1993.

Van SOEST, P.J.; ROBERTSON, J.B.; LEWIS, B.A. Symposium:

Carbohydrate metodology, metabolism, and nutritional implications in dairy cattle. Methods for dietary fiber, neutral detergent fiber, and non-starch polysaccharides in relation to animal nutrition. Journal of Dairy Science, v.74, p.3583-3597, 1991.

YANG, W.Z.; BEAUCHEMIN, K.A.; VEDRES, D.D.; GHORBANI, G.R.; COLOMBATTO, D.; MORGAVI, D.P. Effects of direct-fed microbial supplementation on ruminal acidosis, digestibility, and bacterial protein synthesis in continuous culture. Animal Feed Science and Technology, v.114, p.179-193, 2004.

Data de recebimento: 22/01/2014

Data de aprovação: 19/06/2014 